\title{
A MODO DE PRESENTACIÓN. ESTUDIOS LATINOAMERICANOS SOBRE OTRAS LITERATURAS
}

\author{
Luciana Martinez. \\ lucianamartinez@gmail.com \\ Cristian Molina \\ molacris@yahoo.com \\ Universidad Nacional de Rosario \\ Consejo Nacional de Investigaciones Científicas y Técnicas
}

A la hora de pensar el título del evento de cuyo resultado se desprende el presente dossier (I Encuentro de Estudios Latinoamericanos sobre Otras literaturas, Rosario, 2017) se suscitaron entre quienes fuimos sus organizadoras (ambas coordinadoras asimismo de esta antología) una serie de debates, digamos, de alto voltaje. Y es que la complejidad del asunto lo ameritaba. Por un lado, la motivación de dicha organización respondía a una necesidad imperiosa de pensar las prácticas de lectura, investigación, reflexión y transmisión docente de literaturas tradicionalmente entendidas como "extranjeras" desde Latinoamérica (en nuestro caso circunscripta a las aulas argentinas). Esto implicaba no sólo revisar y repensar ciertos problemas de las literaturas comparadas, los planteos de la literatura mundial y aquellos que se desprenden de las teorías postcoloniales que señalan las dinámicas de construcción cultural desde la periferia, sino también reflexionar sobre el lugar de lo Otro en nuestras producciones locales. Porque, además, por otro lado, pensar las inflexiones de transmisión de Otras literaturas en el 
contexto de la cátedra de Literatura Europea II y Literatura Contemporánea de la UNR suponía enfrentarse a una tradición de problemas un tanto velados.

La mayoría de las que formamos parte de la cátedra, como así también muchas de las figuras destacadas que históricamente ocuparon el lugar de docentes titulares, nos abocamos no sólo al trabajo sobre corpus europeos sino a la investigación de objetos que se recortan dentro de la literatura argentina o más ampliamente latinoamericana. Más aún, si se indaga, es posible percibir que este perfil docente no se circunscribe a las cátedras de la Escuela de Letras de Rosario, sino que es posible rastrearlo conformando una serie que emerge en distintas universidades nacionales. Tal es el caso de ese hombre de "dos literaturas" (como lo llamó Nicolás Rosa) que fue Jaime Rest y de Aldo Oliva, o el de María Teresa Gramuglio, cuya perspicacia crítica puso al servicio tanto de las literaturas comparadas como de la obra de Juan José Saer, por poner algunos ejemplos paradigmáticos; pero también este perfil signa figuras más recientes que se encuentran actualmente en pleno desarrollo del ejercicio docente y de investigación, algunas de las cuales participan en este dossier.

En efecto, una forma válida de pensar la práctica docente de Otras literaturas en Latinoamérica implica tomar, en muchos casos, consciencia sobre una bifrontalidad inherente, cuyo desarrollo suele desalentarse en el ámbito especializado de los claustros. Porque la labor de enseñanza e investigación conforma en ocasiones un campo de interferencia en el que se generan objetos transversales, es decir, objetos que se producen en un cruce de perspectivas ante corpus diversos. En 
ese contexto, la enseñanza de Otras literaturas no podría sino adquirir tintes singulares. Aun en aquellos casos en los que se privilegia la especificidad disciplinar, esto es, la atención exclusiva a la investigación y trasmisión de Otras literaturas, dicho ejercicio se encuentra mediado por tradiciones de lectura y traducción locales; y hasta, a veces, por un cierto "filtro borgeano" que impregna más o menos conscientemente cualquier trabajo con la literatura. En este sentido, nos encontramos persuadidas de que no es lo mismo, no importa el grado de inmersión que el docente tenga en la cultura extrajera, dictar Otras literaturas desde Argentina, que desde Europa, EEUU o, incluso, desde cualquier otro país de Latinoamérica. Y es que cada contexto de trasmisión es inseparable de tradiciones que determinan que eso que se presenta como Otro se resignifique con diversos sentidos. Por eso la reticencia a hablar en términos de "literaturas extranjeras": habilitar el concepto de "Otras literaturas" precisamente permite pensar (siguiendo a Lacan) que eso que se presenta en principio como ajeno, foráneo, extranjero no es sino un Otro que necesariamente nos conforma. El Otro es siempre un Otro-en-mí; y el Otro siempre toma forma a partir de un yo. Leo al Otro desde mi ser en el mundo, pero además, en el caso de Otras literaturas, éstas se resignifican necesariamente en su anclaje dentro de una cadena de interpretaciones históricas previas. Es a partir de ese Otro-enmí que soy, que ese nuevo Otro que eclosiona a la presencia se interpreta.

Se trata, por ende, del concepto de una otredad que resulta, incluso, reversible en sí misma cuando deviene en y con 
nosotras, o, incluso, cuando nuestras culturas se convierten en el foco de estudio de otras literaturas o sistemas culturales. Un modo de la otredad de la literatura que se escurre y se corre de sí y de otras y que, antes que volver a señalar las desigualdades de un mundo política y simbólicamente opresivo, instaura una especie de comunidad conformada por diferencias que, sin embargo, se tocan, contactan, intercambian y producen una multiplicidad incesante. Es, en este sentido, que entendemos el mundo donde las literaturas son otras y nuestras literaturas, al mismo tiempo, pueden ser otras, o en esas otras literaturas también. Esto elude la necesidad de recurrir a conceptos como "centro" o "periferia", "propio" o "ajeno", o trasladar las diferencias a leyes universales, generales y abstractas, para conformar un mundo cuya diferenciación y modos de leer y escribir difícilmente resulten aprehensibles de manera unívoca y monolítica. Como plantea Jean-Luc Nancy:

$\mathrm{Si}$ un mundo es esencialmente, no tanto la representación de un universo (cosmos), ni la de un aquí abajo (mundo rebajado, incluso desahuciado, del cristianismo), sino el exceso, más allá de toda representación de un ethos o de un habitus, de una compostura a través de la cual se sostiene a sí mismo, se configura y expone en sí mismo, se relaciona consigo sin relacionarse con ningún principio dado ni con ningún fin fijado, entonces es necesario ir derecho al principio de una ausencia de principio como ésta. Esto debe denominarse la "sin razón" del mundo, o su ausencia de fundamento. (2002, p. 55) 
Pensar en un mundo implica, de este modo, asumir el riesgo de concebir sin un ethos o un habitus y, por eso mismo, de inventar a partir de una sin razón como fundamento. Se trata de un modo de leer por fuera de las divisiones y jerarquías propias del imperialismo capitalista y de las territorializaciones que arrastramos desde la modernidad. En términos de Nancy, podríamos pensar el mundo como una creación ex - nihilo, es decir, como una nada que crece como algo, o como el crecimiento de una sin razón que es una indefinición que se define siendo y que amerita ser inventada cada vez. Por lo tanto, implica un hacer crítico - en el sentido de una praxis y de una intervención- que inventa de su nada los enunciados creadores de sentido de ese mundo, donde lo que no deja de devenir es una otredad que nos constituye y nos vuelve otros, a su vez, en él.

De este modo, nos permitimos pensar las vinculaciones, las transversalidades y las apropiaciones productivas (e ideológicas) de lo Otro desde Latinoamérica como una proliferación de líneas de investigación, de metodologías y de imaginarios irreductibles. En un reciente artículo publicado en el Dossier 150 años de Charles Baudelaire, por esta misma revista, José Ramón Ruisánchez lee cómo Baudelaire es recibido en México a partir de una metodología de las humanidades digitales, oscilando entre la lectura distante, asegura, y la detenida, puesto que ambas, sostiene, se necesitan. Lo interesante de ese artículo es su propuesta en la discusión dentro del panorama de debate de la "literatura mundial": 
También, de manera paralela y a través de este caso concreto, pienso diferentes maneras de hacer la historia de las literaturas mundiales, subrayando el plural doble, no sólo por concordancia: sino porque creo que existen - precisamente debido a los caminos azarosos por los que, por ejemplo, llega a existir un tal Carlos Baudelaire, que luego irá recomponiéndose en Charles - una literatura mundial argentina y una literatura mundial mexicana que son muy distintas a las que se enseñan en los departamentos de inglés de circuito del Atlántico del Norte. (2018, p. 228)

Es, en este sentido, que entendemos que el trabajo situado con la otredad de la literatura desde Latinoamérica es un modo singular de trabajo que hace mundo y que contribuye a una proliferación de diferencias que deben ser atendidas y no subsumidas en generalizaciones. Sin embargo, si es posible situar nuestros estudios desde Latinoamérica o desde Argentina, eso no debe habilitarnos, tampoco, a esencializar, regional o nacionalmente, un modo de leer o de hacer, pero sí atender a esa proliferación de diferencias en el trabajo con las Otras literaturas. Es por esto que, desde diversas perspectivas, cada uno de los trabajos aquí compilados hacen un aporte valioso a este contexto de discusión y son, en sí, pruebas de ese modo de leer que hace mundo cada vez desde sí en su contacto con lo otro, reinventándose. Las invitamos a leer. 


\section{Referencias Bibliográficas}

Gramuglio, M. T. (2013). Nacionalismo y Cosmopolitismo en la Literatura Argentina. Rosario: Editorial Municipal de Rosario.

Lacan, J. (2014). "Introducción del gran Otro". El Seminario 2. El yo en la teoría de Freud y en la técnica psicoanalítica. Buenos Aires: Paidós. pp. 353-370.

Martinez, L. (2019). "Experiencia y enseñanza de Otras literaturas desde Argentina. Conjeturas en torno a una bifrontalidad", Saga. Revista de Letras, No 9, pp. 248-263

Nancy, Jean-Luc (2002). La creación del mundo o la mundialización. Buenos Aires: Paidós.

Rosa, N. (prólogo y selección) (1981). La crítica literaria contemporánea (Colección Capítulo, $\mathrm{n}^{\circ}$ 113). Buenos Aires: Centro Editor de América Latina.

Ruisánchez, José Ramón (2018). “(Pobre) Baudelaire en México" en Saga. Revista de Letras, No 8, Rosario. 